\title{
UNA SANTA INÉS DE FRANCISCO ANTONIO GIJÓN RECUPERADA.
}

\author{
POR ANTONIO JOSÉ ALBARDONEDO FREIRE
}

La imagen se hallaba depositada en unas dependencias de la iglesia del antiguo convento del Señor San José de la Merced Descalza, donde permaneció después de ser retirada del culto en los años sesenta. En el momento del hallazgo, los responsables de la iglesia desconocía la antigüedad, autoría y trascendencia de la obra, por ello encargaron un estudio histórico y esperan abordar pronto su restauración.

La bibliografía del siglo pasado sobre el patrimonio artístico del convento es posterior al expolio acometido durante la presencia de las tropas francesas, y en estas descripciones, en ningún caso se menciona la existencia en el convento de la imagen de Santa Inés ".

La primera vez de la que tenemos constancia de la existencia de la imagen en la iglesia es a través de un negativo realizado en 1925 conservado en la fototeca del Laboratorio de Arte de la Universidad de Sevilla, en esta fotografía la imagen aparece expuesta en un pequeño retablo del siglo XVIII entonces existente en una capilla lateral de la iglesia en la que permaneció hasta los años sesenta.

Está documentada su exposición, unos años después, en la Sección de Arte Antiguo del Pabellón Mudejar durante la Exposición Ibero-Americana de 1929. ${ }^{2}$

Fue el profesor Bernales quien mantuvo por primera vez la atribución, no documentada, sobre la autoría de la santa en su monografía sobre Francisco Antonio Gijón $^{3}$, pero no llegó a fotografiarla y posiblemente en el momento de la redacción de la obra la imagen ya estuviera retirada del culto.

1. González de León, F.: “Noticias artísticas... de la ciudad de Sevilla”, t. II, p. 164, Sevilla, 1884.

2. Catálogo de la Sección de Arte Antiguo. Exposición Ibero-Americana 1929-30; n787, p. 67. Sevilla, 1929.

3. Bernales Ballesteros, J.: “Francisco Antonio Gijón” en Arte Hispalense, n. 30, p. 106 y 127, Sevilla 1982. 
En julio de 1677 Francisco Antonio Gijón contrató con Fray Juan de la Pasión, sacristán del convento del Señor San José de mercedarios descalzos, la hechura de una Inmaculada Concepción que hoy se encuentra en paradero desconocido; por aquel año, el artista también contrató con las monjas de la misma Orden los relieves para dos retablos y una imagen del Niño Jesús ${ }^{4}$. Dada esta estrecha relación entre Gijón y la orden de la Meced Descalza y, considerando los rasgos moderados de la obra podemos sostener la datación de la imagen de Santa Inés, como ya hiciera Bernales, entorno al año de $1677^{\mathrm{s}}$.

La santa recuperada, de un metro y quince centímetros de altura, está concebida como una joven de gran belleza y elegancia. En ella la atención se concentra en las suaves torsiones del cuerpo envuelto en un amplio manto que deja ver los volúmenes anatómicos. Los tejidos aún no se proyectan hacia el exterior como ocurrirá en los trabajos de las últimas décadas del siglo XVII. La indumentaria, que está trabajada con el nervioso plegado que responde al peculiar estilo de Gijón, ayuda a acentuar el "contrapposto" por medio de sus pliegues, aportando movimiento y claroscuro a la composición. La cabeza de la joven santa, de esbelto cuello, fue esculpida con un aderezo de cabello que le otorga cierto aire oriental. El rostro posee aquella mirada melancólica tan frecuente en los trabajos de Gijón realizados durante su segundo matrimonio, la cual le concede cierta presencia introspectiva que ayuda a acrecentar los hermosos rasgos de la santa.

Posiblemente se trata de uno de los primeros trabajos pertenecientes a la época del autor que Bernales llama de "estabilidad", que va de 1677 a $1682^{6}$. Aunque Gijón sólo tenia veintitrés años, demuestra en la ejecución que ha alcanzado la definición de su estilo, en sus obras, dejando atrás las vacilaciones e incorrecciones de las obras de juventud.

La escultura se encuentra en buen estado de conservación, mantiene la policromía original y tan sólo requiere una limpieza y consolidación de ciertos ensambles que han provocado algunas grietas en el rostro, en el cuello y en las manos.

4. Bernales Ballesteros, J.: Ibídem, p. 72-74 y 120.

5. Bernales Ballesteros, J.: Ibídem, p. 106.

6. Bernales Ballesteros, J.: Ibídem, p. 72-80. 


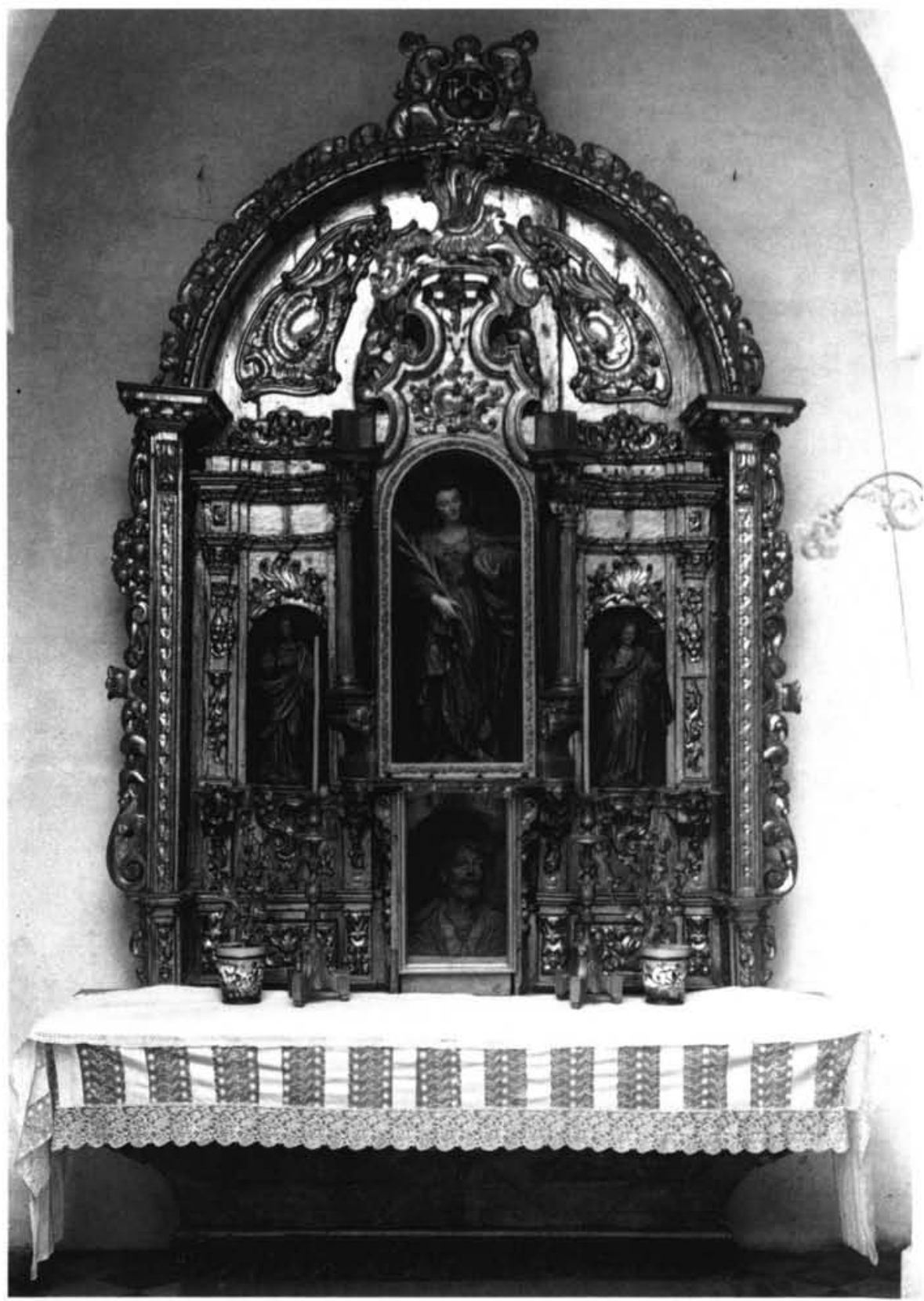

Lám. 1

SANTA INÉS. Francisco Antonio Gijón. Iglesia del Señor San José de Sevilla. Hacia 1677. Mide: $115 \mathrm{~cm}$. Imagen expuesta en un pequeño retablo del siglo XVIII entonces existente en una capilla lateral de la iglesia y hoy perdido. Fototeca del Laboratorio de Arte. 1925. 


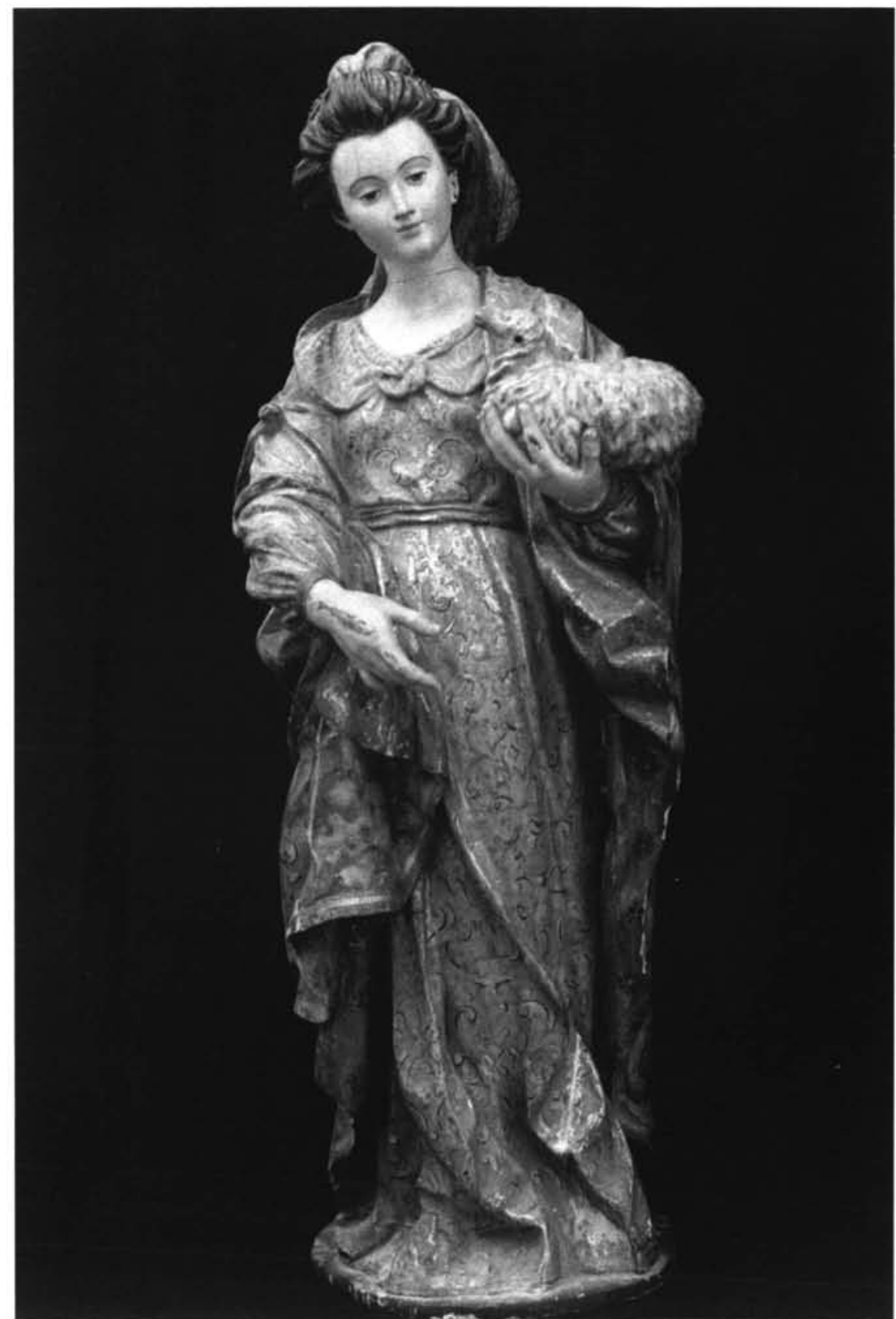

Lám. 2

SANTA INÉS. Francisco Antonio Gijón. Iglesia del Señor San José de Sevilla. Hacia 1677. Mide: $115 \mathrm{~cm}$. Foto: L. A. P. M. 


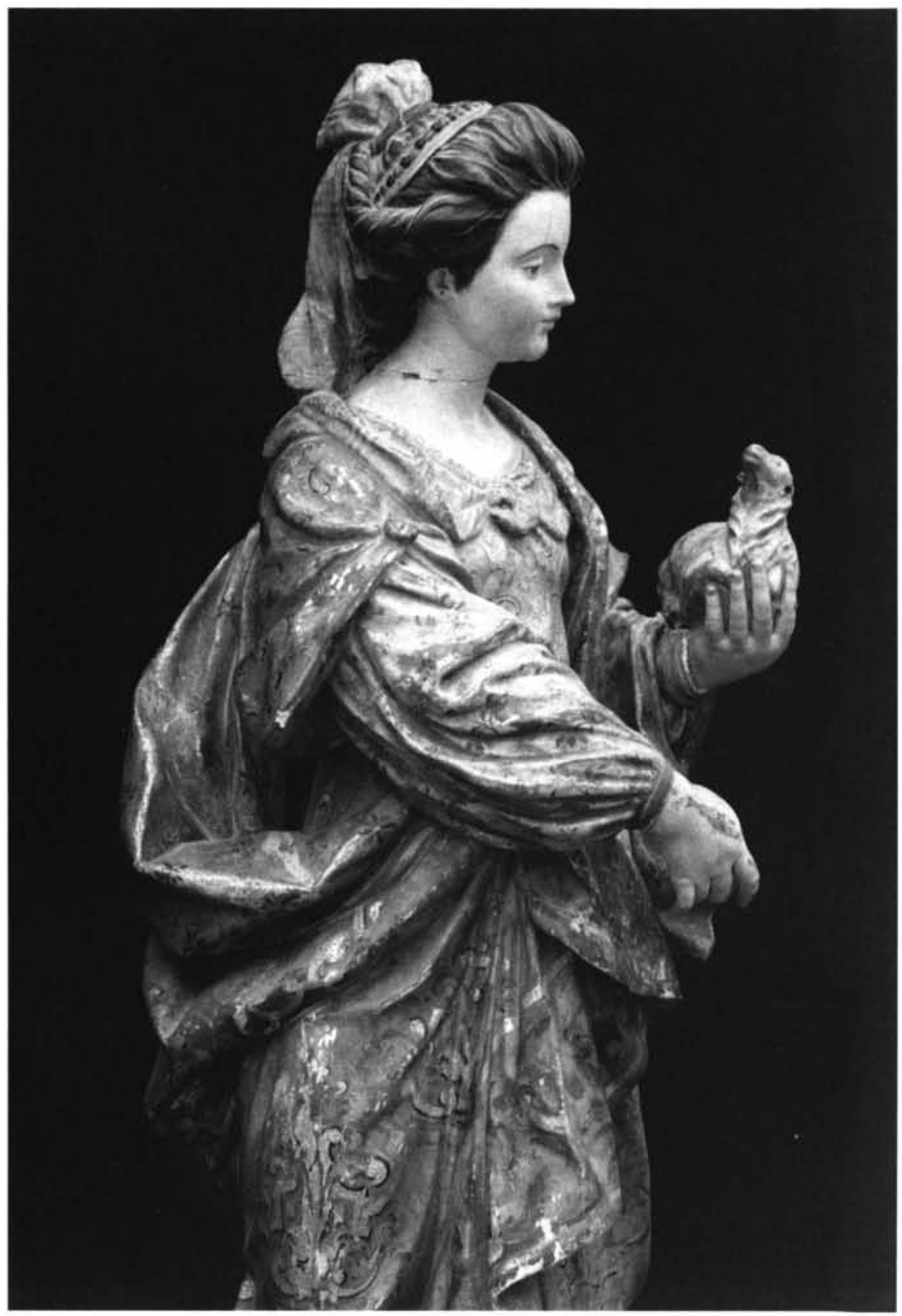

Lám. 3

SANTA INÉS. (detalle del perfil derecho). Francisco Antonio Gijón. Iglesia del Señor San José de Sevilla. Hacia 1677. Mide: $115 \mathrm{~cm}$. Foto: L. A. P. M. 